\title{
Genome editing: development and regulatory challenges
}

\author{
Mikhail Y. Samsonov \\ JSC RPharm, Moscow, Russia
}

\begin{abstract}
Dr. Mikhail Y. Samsonov, PhD, Chief Medical Officer, JSC RPharm, Russia, 111B Leninsky prospect, 197002, Moscow, Russia
\end{abstract}

\section{Summary}

Genome editing tools can be mostly used to introduce, remove, or substitute one or more specific nucleotides at a specific site in an organism's genome, and is achieved with the use of protein-nucleotide complexes. Several classes of these complexes exist, Zinc Finger Nuclease (ZFN), transcription activator-like effector nuclease (TALEN and the most recent discovery - Clustered regularly interspaced short palindromic repeats /CRISPR associated protein 9 (CRISPR/Cas9). The technology belongs to a growing list of personalized therapies and requires special attention to perform development, standardization of manufacturing for every patient, robust preclinical and clinical program addressing key challenges of the new technology, e.g. "off-target" effects. The ethical aspects of these tools are also quite critical.

\section{Keywords}

Genome editing, ZFN, TALEN, CRISPR-Cas9, regulatory environment, benefit $\backslash$ risk evaluation.

\section{Introduction}

The progress in genome editing over the last three decades has been accompanied by the development of appropriate legal regulations and ongoing discussions of their implementation into real practice.

In this article, we will focus primarily on current regulatory practice supporting development of the first clinically oriented products for treatment of disease, such as HIV, Hepatitis B and cancer. Moreover, regulations and guidance are still developing especially, in Russia and will require a permanent dialogue between regulatory agencies and scientists [14].

The logic of product development, addressing scientific questions and engagement to a regulatory dialogue, may be based on the following principles:

- Unique requirements for each genome-edited cell product (GECP) require a case-by-case review, aiming to comply with current local guidelines (or discuss how they are not relevant to this product);

- For most cases, there is lacking knowledge on potential clinical consequences, thus requiring cautious approaches to be taken;
- Regulatory authorities should be interested in partnership with developers of genome-editing technology, thus ensuring its sooner access to patients.

Generally, genome editing therapy (ex vivo or in vivo manipulations) will determine a significant part of preclinical and clinical study program. Similarly, the type of product will impact main characteristics of manufacturing process. Usage of mock product (individual cell material from donors or patients) is acceptable since it is needed to assure quality of process development and characterization for personalized approaches, especially for ex vivo applications. This implementation strategy is very similar to evaluation of cell products.

\section{Genome editing: variety of tools and products}

Three genome editing tools are mostly used now: ZFN and TALEN systems which are at a more advanced stage, and CRISPR/Cas9 being in very early clinical development, thus providing us an opportunity to proceed with their further development and regulatory discussions $[14,16]$. 
Moreover, type of genome editing therapy (either ex vivo, or in vivo manipulation) will generate, at least, two specific questions:

1. Should be an ex vivo genome editing therapy tested prior to reinfusion into patients, and how should it be performed?

A great deal of sterility assurances and processes (including fluorescent flow cytometry and cell sorting (FACS techniques) should be applicable for the machines used to sort each patients' cells. This is considered to have a slightly better safety profile due to appropriate control and tests that can be conducted ex vivo to reassure quality of the cells (end product) that is returned to the patients. Fast-developing CAR-T cell products are a good example of this therapy [12].

2. Should be the applied therapy used for in vivo gene modifications?

These genome-modified cell products require more preclinical (molecular biology, in vitro)) data to understand their mechanism of action (MOA) and proliferation pathways. Moreover, specific activity of such products cannot be stopped even after a single injection, if some self-limiting mechanism is not provided [15]. Hence, a self-inactivation activity of a viral vector driven by a switch-off mechanism could be also developed. At the same time, additional virus-shedding studies are required to test levels of target gene expression and their time frames [8]. Long term clinical safety data will be also required for evaluation of vector-driven products, most possibly, for 5 years and more (longer terms are possible, for post-market availability, expecting large benefits observed due to high demand for the product) $[10,14]$.

Potential off-target activity is another critical challenge for in vivo gene modifications. It's well known that ZFN and TALEN are more site-specific and generate less regulatory concerns. CRISPR\Cas9 has more variability and causes serious challenges due to possible off-target activity especially in vivo modifications. A recent publication in Molecular Therapy [18] has reported that high levels of additional mutations in mice treated with CRISPR/Cas9 generated attention and debates on this aspect [18]. In a letter published June, 2017, the researchers reported a whole genome sequencing study which showed uncovered more than 1,600 genetic differences between the two mice treated with CRISPR/Cas9 technology, and 1 untreated control [17]. The authors concluded that CRISPR/Cas9 may be much less precise than previously expected [17]. Not surprisingly, the publications received a great deal of pushback from CRISPR companies and researchers criticizing the study, its methodology, and conclusions. In a Letter to The Editor, the authors replied that the analysis showed a "striking similarity" for single nucleotide variants (SNV) and insertions, deletions (indels) across the genome between treated mice that suggesting "either underlying genetic similarities or a mutagen that is strongly directive." In addition, the authors compared the SNV and indels variant list against the mouse reference genome, and found the variants that were distributed in a way that a mutagen such as CRISPR "is unlikely to be causative for these observed variants.” [4]. Undoubtedly, regulatory bodies will have their say by providing feedback to requests addressing this challenge, or even by publishing guidelines for off-target evaluation.

\section{Product characterization}

The genome-modified cell description will depend on nature and purpose of the product and could fall into:

(a) Genome therapy medicinal product (GTMP) described by special EMA guidelines (10) or FDA one [7-8] or

(b) Cell product based on CAR T and other types of ex vivo genome editing therapy [6-11]

Since these treatments may be applied for treatment of rare diseases, batches manufactured according to GLP standards (Good Laboratory Practice) can be used for phase 1/2, with additional controls expected for phase $2 / 3$ studies in a significant number of countries $[6,8,9]$. Russian regulations require GMP materials for clinical studies $[1,2]$. The remaining cautions are typically expected for biological research aimed for clinical trials and commercial manufacturing. Review and discussion with Agencies (EMA, FDA etc) will help to clarify the issues and will be considered case by case.

A very important point for product characterization of non-viral in vivo delivery therapy will depend on description of physical methods (for example, electroporation and microfluidic-based technologies), nanomaterial-based methods (for example, cationic lipids and cell penetrating peptides) and self-assembled nanoparticles (more classical characterization from regulatory point of view). Viral delivery may utilize different viral vectors (for example, lentiviruses, AAVs, or adenoviruses), to pack the gene of interest, as RNA or DNA form, in order to facilitate its efficient delivery [19].

On the ex vivo side, CAR $\mathrm{T}$ is developing to the following directions [16]:

1. Individual patient-specific product as a quite labor-intensive process which requires conduction of a number of mock validation runs;

2. Universal or allogenic 'off-the shelf' CAR T product with similar regulatory characterization methodology as for to biopharmaceuticals.

\section{Preclinical}

Detailed preclinical program will be build a case by case with clear justification of conducted studies. In general, one cannot omit all preclinical/non clinical developments due to rarity of a disease and its target. Disease-specific animal models with appropriate functional outcomes are preferred in such situations, but it is understood that sometimes only 'off-target' preclinical models can be used. In this case, a relevant animal with similar DNA targets and use of surrogates makers is expected to check ensure activity of the product in this animal model.

A great deal of focus is on the proof-of-concept (POC) animal studies, as these provide a reason to believe in the technology to agencies and sponsors, and this is crucial for first trial in human (FIH) but also for EMA Orphan Drug applications. For vector products expression, the studies need to be conducted with rather long follow-up time (6 months possible for FIH, 12 months or more) for phase $2 / 3$. 


\section{Clinical}

Clinical Program with phase $1 / 2$ and one final phase 3 study are possible to consider enough to register. The studies will take a lot of time and will require staggered enrollment and dose escalation, especially in the FIH study $[8,10]$. The phase 1 approach includes a classical oncology dose escalation/cohort approach of enrolling one patient at a time, for a total of 3 per dose cohort, with waiting periods of up to 20-30 days. Prior dose to next patient in any given cohort depends on the product profile and expected time frame to observe the most serious common adverse events. This is a cautious approach given the limitations of many preclinical models $[9,14]$.

By the present time, there is a number of phase 1-2 studies designed in order to treat rare disease, cancer and viral disease. In vivo studies are required when developing an 'off switch' mechanism by introducing suicide gene into the modified cell product triggering apoptosis or molecules terminating in vivo editing [16].

\section{Regulatory trends}

EMA and FDA are maintaining a product-focused, science-based regulatory policy $[5,11,14]$. Human medical products that apply gene editing to exert their therapeutic effect are regulated under the existing framework for biological products, which include gene therapy products [5-11]. "Gene editing" here refers to non-heritable situations with somatic cell gene therapy only, and not to heritable conditions (germline gene therapy). FDA's Center for Biologics Evaluation and Research (CBER) has a well-established program and policies in place to evaluate gene therapy products in their newly formed Office of Tissues and Advanced Therapies (OTAT, formerly known as the Office of Cellular, Tissue and Gene Therapies, or OCTGT). Although different types of gene editing have potential clinical applications, currently only one type of gene editing, namely, zinc finger nuclease- (ZFN)-mediated, has been announced by their sponsors as being applied in clinical trials, being underway in the United States. Proposals for NIH-funded human gene therapy clinical trials are discussed and reviewed for scientific, clinical, and ethical issues by the NIH's Recombinant DNA Advisory Committee (RAC). The RAC recently discussed and did not find any objections to the first clinical protocol to use CRISPR/Cas9-mediated gene editing. The potential for "off-target" effects such as insertions or deletions at unintended genetic loci are considered by experts in the field as a key concern.

Interestingly, FDA also has a longstanding collaborative relationship with the NIH office that oversees the RAC. FDA serves as a non-voting liaison on the committee, hears the discussions first-hand, and receives the written recommendations. These recommendations may be considered during our overall review of investigational new drug applications (INDs) submitted to FDA.

EMA is following similar approach having establishing a category of products termed Advanced therapy medicinal products (ATMPs) for medicines for human use that are based on genes or cells. In addition EMA established a Com- mittee for Advanced Therapies (CAT) which plays a central role in scientific assessment of advanced therapy medicines. It provides the expertise that is needed to evaluate advanced therapy medicines. The use of a newly launched PRIME mechanism for early scientific dialogue can also be used with these therapies [5].

Three main regulations are covering the genome editing in Russia:

- Federal Law \#180 FZ - ex vivo and it looks CART technologies will fall under this law [1];

- Federal Law \#61 FZ - in vivo [2];

- Federal Law \#83 FZ - broader range of transgenic products [3].

The key need is to have across laws guidance dedicated to common aspects of analytical evaluation, manufacturing, preclinical and clinical development similar to EMA or FDA.

\section{Ethical aspects and next steps}

"A triangle of considerations - extraordinary suffering, highly penetrant genotypes, and justifiable interventions - has, thus far, constrained our attempts to intervene on humans. As we loosen the boundaries of this triangle (by changing the standards for "extraordinary suffering" or "justifiable interventions", we need new biological, cultural, and social precepts to determine which genetic interventions may be permitted or constrained, and the circumstances in which these interventions become safe or permissible" [15].

National regulations in many countries including Russia restrict or prohibit research in which human embryo is intentionally created or modified, including a heritable genetic modification [12].

Legal supervision provided by EMA, FDA and other agencies is one aspect of broader governance necessary for safe and responsible research and development of genome editing applications. Moreover, the expansive scope of intentional genomic alterations using modern genome editing technologies has triggered debate on fundamental ethical and social issues, which will continue to influence public opinion and acceptance of genome editing applications. Even as regulatory agencies implements necessary steps for effective regulation to ensure the safety of products, the role of broader, inclusive public discussion involving multiple constituencies (e.g., scientists, developers, bioethicists, and public interest and community groups) to address the larger societal considerations should not be overlooked.

\section{Conflict of Interest}

No conflict of interest are declared.

\section{Acknowledgements}

The author is grateful to colleagues for their excellent support and challenging questions during the manuscript preparation. 


\section{References}

1. Federal Law No. 61-FZ. On the Turnover of Medical Drugs. Moscow, 12.04.2010 (In Russian).

2. Federal Law No. 86-FZ On State Regulation in Gene Engineering Activities. Moscow, 05.07.1996 (In Russian)

3. Federal Law No. 180-FZ. On Biomedical Cell Products, Moscow, 23.06.2016 (In Russian).

4. Bothmer A, Maeder ML, Reyon D et al. The experimental design and data interpretation. In: Schaefer KA, Wu WH, Colgan DF, Tsang SH, Bassuk AG, Mahajan VB. Unexpected mutations after CRISPR-Cas9 editing in vivo are insufficient to support the conclusions drawn by the authors. Nat Methods. 2017; 14(6):547-548. bioRxiv Jun. 21, 2017; doi: http:// dx.doi.org/10.1101/153338.

5. Enhanced early dialogue to facilitate accelerated assessment of PRIority MEdicines (PRIME), EMA/ CHMP/57760/2015, 25 February 2016, 1-12

6. Draft guidance for industry and Food and Drug Administration staff, Minimal manipulation of human cells, tissues, and cellular and tissue-based products., FDA , December 2014, 1-9

7. Guidance for industry. Potency test for cellular and gene therapy products. FDA; January 2011, 1-17.

8. Guidance for industry, design and analysis of shedding studies for virus or bacteria-based gene therapy and oncolytic products. FDA; July 2014:1-17.

9. Guidance for industry. Preclinical assessment of investigational cellular and gene therapy products. FDA; November 2013:1-32.
10. Guideline on the quality, non-clinical and clinical aspects of gene therapy medicinal products. European Medicines Agency. 2015; EMA \CAT \80183\2014: 1-42

11. Guideline on human cell-based medicinal products, European Medicines Agency. 2008; EMEA/CHMP/410869/2006: $1-25$

12. Kingwell K. CAR T therapies drive into new terrain, Nature Review Drug Discovery, 2017; 16:301-304.

13. Mukherjee $S$, The gene. An intimate history, Scribner Publ,: N-Y; 2016: 1-592.

14. Narayanan G, Cossu G, Galli MC. Clinical development of gene therapy needs a tailored approach: a regulatory perspective from the European Union, Human Gene Therapy Clinical Development. 2014, 25: 1-6.

15. Pawluk A, Amrani N, Zhang Y, Garcia B, Hidalgo-Reyes Y, Lee J, Edraki A, Shah M, Sontheimer EJ, Maxwell KL, Davidson ARl. Naturally occurring off-switches for CRISPR-Cas9. Cell. 2016; 167(7): 1829-1838.e9.

16. Popova MO, Lepik KV, Sergeev VS, et al. Clinical implementation of genome editing for correction of human disease. Cell Ther Transplant. 2017; 6(1): 35-40.

17. Schaefer KA, Wu WH, Colgan DF, Tsang SH, Bassuk AG, Mahajan VB. Unexpected mutations after CRISPR-Cas9 editing in vivo. Nature Methods 2017:14(6): 547-548.

18. Wu WH, Tsai YT, Justus S, Lee TT, Zhang L, Lin CS, Bassuk AG, Mahajan VB, Tsang SH. CRISPR repair reveals causative mutation in preclinical model of retinitis pigmentosa. Mol Ther. 2016; 24:1388-1394.

19. Yin H, Kauffman KJ, Anderson DG. Delivery technologies for genome editing. Nature Reviews Drug Discovery. 2017;16:387-399.

\title{
Редактирование генома: разработка и проблемы регулирования
}

\author{
Михаил Ю. Самсонов \\ ОАО Р-Фарм, Москва, Россия
}

\section{Резюме}

Технологии редактирования генома могут быть чаще всего использованы для введения, удаления или замещения одного или нескольких нуклеотидов в определенном месте генома, и они осуществляются с применением белок-нуклеотидных комплексов. Известно несколько классов подобных комплексов: нуклеазы типа Zinc Finger (ZFN), нуклеазы типа TALEN и недавно открытые комплексы типа CRISPR/Cas9. Эти технологии относятся к растущему списку методов персонализированной терапии и требуют особого внимания в плане развития, стандартизации производства для каждого больного, эффективных доклинических и клинических программ, касающихся основных проблем новой технологии, например - побочных («внецелевых») эффектов. Весьма важными являются также этические аспекты применения этих технологий.

\section{Ключевые слова}

Геномноередактирование,ZFN, TALEN, CRISPR/Cas9, юридические правила, оценка выгоды/риска. 